Artículo científico

Volumen 32(2):487-507. Mayo-agosto, 2021

e-ISSN 2215-3608, doi:10.15517/am.v32i2.43794

https://revistas.ucr.ac.cr/index.php/agromeso/index

\title{
Prevalencia, incidencia y factores de riesgo de mastitis subclínica en lecherías especializadas en Colombia ${ }^{1}$
}

\section{Prevalence, incidence and risk factors of subclinical mastitis in specialized dairies in Colombia}

\author{
Catalina Medrano-Galarza², Diego Germán Ahumada-Beltrán², Juan José Romero-Zúñiga , \\ Pilar Donado-Godoy²
}

1 Recepción: 9 de setiembre, 2020. Aceptación: 21 de enero, 2021. Este trabajo formó parte de un proyecto llevado a cabo por la Corporación Colombiana de Investigación Agropecuaria (AGROSAVIA) con recursos del Ministerio de Agricultura y Desarrollo Rural y del Ministerio de Ciencia, Tecnología e Innovación - Minciencias de Colombia.

2 Corporación Colombia de Investigación Agropecuaria (AGROSAVIA). Centro de investigación Tibaitatá. Mosquera, Cundinamarca, Colombia. cata.medrano@outlook.com (autor para la correspondencia; https://orcid.org/0000-0002-2690-189X), dahumada@agrosavia.co (https:// orcid.org/0000-0002-6837-0863), pidonado@agrosavia.co (https://orcid.org/0000-0001-9839-9264).

3 Universidad Nacional. Escuela de Medicina Veterinaria. Heredia, Costa Rica. juan.romero.zuniga@una.ac.cr (https://orcid.org/0000-00025252-1604).

\section{Resumen}

Introducción. La mastitis subclínica (MSC) es una de las principales enfermedades en bovinos; estudiar su epidemiología es fundamental para implementar programas de salud. Objetivo. Determinar la prevalencia, la incidencia y factores asociados a la mastitis subclínica en lecherías especializadas en Cundinamarca, Colombia. Materiales y Métodos. Se realizó un estudio observacional-analítico, de cohorte-prospectivo. Quince fincas se visitaron tres veces cada 56 días (septiembre-2019 a febrero-2020). En cada visita se realizó la prueba California (CMT), se evaluó suciedad de ubres y miembros posteriores de vacas lactantes y la rutina de ordeño. Se recolectó una muestra de leche por finca para determinar recuentos de células somáticas (RCS) y bacterias (RB). Modelos de regresión logística mixtos se usaron para determinar factores asociados con tener o adquirir MSC, y modelos lineales generalizados para determinar factores asociados a mayor prevalencia de MSC y RB. Se realizaron 960 CMT a 454 vacas. Resultados. Se realizaron 960 CMT a 454 vacas. La prevalencia de MSC (mediana) a nivel-hato fue $50 \%$, y estuvo directamente asociada con RCS y RB. La incidencia acumulada (mediana), a nivel-hato, para desarrollar una infección nueva y una crónica fue $42 \%$ y $75 \%$, respectivamente. Factores asociados con tener MSC fueron: multiparidad (Odds ratio: $\mathrm{OR} \geq 2,35)$, lactancia tardía $(\mathrm{OR}=3,39)$, no presellar $(\mathrm{OR}=1,74)$ y sobreordeñar $(\mathrm{OR}=1,96)$. Factores que redujeron el riesgo de adquirir MSC fueron: tener $<3$ lactancias $(\mathrm{OR} \leq 0,29)$, lactancia temprana-media $(\mathrm{OR} \leq 0,32)$, segregación $(\mathrm{OR}=0,37)$ y presellar $(\mathrm{OR}=0,27)$. Factores asociados con la probabilidad de una mayor prevalencia de MSC fueron: no segregar $(\mathrm{OR}=2,42)$, ni presellar $(\mathrm{OR}=2,50)$. Factores asociados con elevados $\mathrm{RB}$ fueron: ubres sucias, tiempo de acción del presellador menor a 30 s y tener más de un ordeñador. Conclusión. Multiparidad, lactancia tardía (>180 dias en producción), no segregar, no presellar y sobreordeñar, fueron los factores que se asociaron con adquirir y tener mastitis subclínica, por lo tanto, se deben tener en cuenta en medidas de prevención y control.

Palabras clave: ganado bovino, incidencia, prevalencia, prácticas, salud de ubre. 


\begin{abstract}
Introduction. Subclinical mastitis (SCM) is one of the main diseases in cattle; studying its epidemiology is essential to implement health programs. Objective. To determine the prevalence, incidence, and factors associated with subclinical mastitis in specialized dairies in Cundinamarca, Colombia. Materials and methods. An observational-analytical, prospective-cohort study was performed. Fifteen farms were visited three times every 56 days (September-2019 to February-2020). At each visit, the California test (CMT) was performed and dirtiness of udders and hind limbs of milking cows was evaluated; likewise, milking routine was evaluated. One milk sample per farm was collected to determine somatic cell counts (SCC) and bacteria count (BC). Logistic regression mixed models were used to determine factors associated with having or acquiring SCM, and generalized linear models to determine factors associated with the probability of a greater prevalence of SCM and BC. 960 CMT were performed on 454 cows. Results. A total of 960 CMT were performed on 454 cows. The median herd-level prevalence of SCM was $50 \%$ and it was directly associated with SCC and BC. The median cumulative herd-level incidence of developing a new and a chronic infection of SCM was $42 \%$ and $75 \%$, respectively. Factors associated with having SCM were: multiparous cows (Odds Ratio, $\mathrm{OR} \geq 2.35$ ), late lactation ( $\mathrm{OR}=3.39)$, no pre-dipping ( $\mathrm{OR}=1.74)$, and over-milking ( $\mathrm{OR}=1.96)$. Factors that reduced the risk of acquiring SCM were: having $<3$ lactations $(\mathrm{OR} \leq 0.29)$, early-mid lactation $(\mathrm{OR} \leq 0.32)$, segregating cows $(\mathrm{OR}=0.37)$, and pre-sealing $(\mathrm{OR}=0.27)$. Factors associated with the probability of a greater prevalence of SCM were: not segregating $(\mathrm{OR}=2.42)$ and not pre-dipping $(\mathrm{OR}=2.50)$. Factors associated with increased $\mathrm{BC}$ were: dirty udders, pre-sealer action time less than $30 \mathrm{~s}$, and having more than one milker. Conclusion. Multiparous cows, late lactation (>180 days in production), not segregating, not pre-sealing, and over-milking, were factors associated with acquiring and having subclinical mastitis, therefore, they are key factors to consider in prevention and control measures.
\end{abstract}

Keywords: cattle, incidence, prevalence, practices, udder health.

\title{
Introducción
}

La mastitis es la inflamación de la glándula mamaria y, según las características organolépticas de la leche, es clasificada como subclínica o clínica, siendo la primera la predominante (Viguier et al., 2009). En Colombia, en un estudio realizado en Sabana de Bogotá, en veinticinco fincas de lechería especializada, se encontraron prevalencias de 0 a $59 \%$ para mastitis subclínica (MSC) y de 0 a $7 \%$ para mastitis clínica (Medrano-Galarza et al., 2020). Una vaca con MSC, generalmente es diagnosticada con la prueba de California (CMT) o al evaluar el recuento de células somáticas (RCS) en su leche. Estas pruebas se han establecido como herramientas de manejo de salud de hato en lecherías especializadas (Ruegg, 2017).

La mastitis es considerada una de las enfermedades más importantes en el ganado lechero, así como una de las enfermedades más dolorosas y que generan un problema no solo económico sino de bienestar animal en bovinos (Mainau et al., 2014). Vacas con mastitis clínica presentan cambios comportamentales indicativos de dolor (Siivonen et al., 2011); pero incluso, hay evidencia que vacas con MSC tienen un umbral térmico nociceptivo más bajo a nivel de la ubre que vacas sanas (Peters et al., 2015). Las pérdidas económicas que genera la mastitis clínica están relacionadas directamente con el descarte de leche y los costos de tratamiento, e indirectamente con el descarte de animales (Blowey \& Edmondson, 2010; Suárez et al., 2017). Los componentes más importantes del costo de la MSC son la reducción en la producción y calidad de la leche (alto RCS) y el descarte de animales (Aghamohammadi et al., 2018), el primero más pronunciado en fincas pequeñas y medianas respecto a las grandes (Romero et al., 2018). Adicionalmente, varios estudios han demostrado el impacto negativo de la mastitis clínica y subclínica en la fertilidad de las vacas (Ruegg, 2017), lo que evidencia la importancia de reducir su incidencia en los hatos. 
La mastitis es una enfermedad de múltiples causas, pero décadas de investigación han señalado la importancia de varias prácticas preventivas asociadas a la buena preparación de la ubre y al proceso de ordeño (Ruegg, 2017). La buena preparación de la ubre se refiere a los diferentes pasos necesarios para tener una ubre lista para el ordeño, tales como la limpieza de los pezones, el despunte y el uso de una solución desinfectante (presellador), sumado a la práctica de sellado de cada pezón al final del ordeño (Ruegg, 2017). Sin embargo, a pesar de tener una mayor adopción de este tipo de prácticas por parte de los productores en países como Estados Unidos de América y Canadá (Belage et al., 2017a), en Colombia la adopción ha sido poca, adicional a la limitación en la información diagnóstica del sector lechero.

En un estudio realizado en hatos lecheros en Antioquia, ninguna finca implementaba el presellado, $50 \%$ de las fincas secaba los pezones y solo $30 \%$ de las fincas utilizaba sellador al finalizar el ordeño (Silva-Pulido et al., 2014). La diferencia en niveles de adopción, está relacionada directamente con la exigencia de las plantas procesadoras por leche de buena calidad, que se refleja en el pago por litro de leche. Esto ha sido una forma de motivar la adopción de estas prácticas (Ruegg, 2017). Para promover la aceptación de recomendaciones, no siempre funciona el proporcionar a los productores explicaciones generales y obtenidas de contextos que no resultan familiares al productor en su propia realidad (Ritter et al., 2017). Teniendo en cuenta lo anterior y la importancia de generar conocimiento local y construir recomendaciones basadas en datos locales, el objetivo de este trabajo fue determinar la prevalencia, la incidencia y factores asociados a la mastitis subclínica en lecherías especializadas en Cundinamarca, Colombia.

\section{Materiales y métodos}

\section{Descripción del área de estudio}

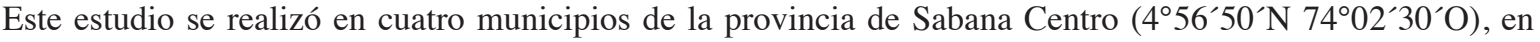
el departamento de Cundinamarca, a nivel de la parte central de la cordillera oriental de los Andes, Colombia. Los municipios fueron Zipaquirá, Cogua, Nemocón y Tocancipá, los cuales están ubicados a 55, 31, 65 y 47 km, respectivamente, de Bogotá D.C (capital de Colombia) (Gobernación de Cundinamarca, 2018) y tienen aproximadamente 130, 22, 13 y 39 mil habitantes, respectivamente (Departamento Administrativo Nacional de Estadística, 2018). La altitud media de estos municipios es $2632 \mathrm{msnm}$ (trópico alto), con una temperatura media anual de $14{ }^{\circ} \mathrm{C}$ (Gobernación de Cundinamarca, 2018). La producción de leche bovina es una de las actividades principales de esta región y la realizan en su mayoría por pequeños y medianos productores (hatos de $\leq 25$ vacas en ordeño o entre 26 y 100 vacas, respectivamente) (Romero et al., 2018).

\section{Fincas, visitas y mediciones}

Quince fincas de lechería especializada pertenecientes al Comité de Ganaderos Área 5 (Zipaquirá, Cundinamarca, Colombia) participaron en este estudio. Las fincas se seleccionaron por conveniencia con base en la disposición de los productores por participar. Cada finca se visitó tres veces, con intervalos de aproximadamente 56 días, entre septiembre de 2019 y febrero de 2020 (visita 1: septiembre-octubre 2019; visita 2: noviembre-diciembre 2019; visita 3: enero-febrero 2020). Durante la visita a las fincas se realizó la prueba CMT y la clasificación del grado de suciedad de la ubre y los miembros posteriores de todas las vacas en producción; además, se evaluaron las prácticas de manejo durante el proceso de ordeño. Los datos individuales sobre número de lactancias y días en producción (DEP), se obtuvieron a través del historial de cada vaca registrado en el programa para manejo de hatos VAMPP Bovino 3.0 (Universidad Nacional-CRIPAS, Heredia, Costa Rica; Romero-Zúñiga et al., 2019). 


\section{Diagnóstico de mastitis subclínica}

Para diagnosticar la MSC de cada vaca, se usó la prueba CMT, la cual utiliza una escala de cinco-puntos (Ruegg, 2003; Adkins \& Middleton, 2018). Se consideró un resultado RCMT negativo (RCMT=0) si la mezcla de leche y reactivo para CMT permanecía líquida, sin evidencia de precipitación. Si la mezcla presentaba un precipitado que desaparecía con el movimiento continuo, el resultado se clasificó como trazas (RCMT=T). Cuando la mezcla presentó un precipitado que no desaparecía con el movimiento, pero sin formar gel, se clasificó como positivo grado $1(\mathrm{RCMT}=1)$; si la mezcla se espesaba inmediatamente y se formaba un gel, se clasificó como positivo grado 2 (RCMT=2); y si hubo una fuerte formación de gel con una superficie convexa, se clasificó como positivogrado 3 (RCMT=3). En este estudio, se consideró que una vaca tenía MSC si presentaba un RCMT $\geq 1$ en al menos uno de los cuartos. Adicionalmente, si las vacas estuvieron presentes en dos pruebas consecutivas de CMT, a partir de la comparación de sus dos mediciones, se procedió a clasificar su estado de MSC como caso nuevo, crónico o recuperado. La clasificación del estado de infección se basó en la metodología descrita por Cardozo et al. (2015), donde una vaca se consideró: (1) saludable si RCMT $<1$ en la visita previa y RCMT $<1$ en la visita siguiente; (2) recién infectada (caso nuevo) si RCMT $<1$ en la visita previa y RCMT $\geq 1$ en la visita siguiente; (3) recuperada si RCMT $\geq 1$ en la visita previa y RCMT $<1$ en la visita siguiente; y (4) crónicamente infectada si RCMT $\geq 1$ en dos visitas consecutivas.

\section{Evaluación del grado de suciedad}

En cada visita, durante el ordeño, se evaluó la condición de limpieza a nivel de miembros posteriores y ubre, utilizando la escala de cuatro puntos descrita por Schreiner \& Ruegg (2003), donde un puntaje de 1 indicaba que el área estaba totalmente limpia (toda el área limpia, sin suciedad), 2 = área ligeramente sucia (menos de la mitad del área está cubierta de suciedad- tierra, materia fecal), 3 = área en su mayoría sucia (la mitad del área o más está cubierta de suciedad), y 4 = área completamente cubierta con suciedad.

\section{Prácticas de manejo durante el proceso de ordeño}

En cada visita se observó la rutina de ordeño desde el momento en que el trabajador iba a recoger al ganado al potrero hasta que la última vaca salió de su puesto de ordeño. La persona que observó el ordeño registró el número y género de ordeñadores, si hubo cambio de ordeñadores (respecto a la visita previa), el tipo de actitud del trabajador al traer los animales al sitio de ordeño (calmado vs. afanado-agresivo), la condición de limpieza (suciaembarrada vs. limpia-seca) del sitio de espera pre-ordeño, del sitio de ordeño y de la zona de salida del puesto de ordeño; además, si se realizaba segregación en función de la presentación de casos de mastitis (orden de entrada), el uso de guantes por parte del ordeñador, si se implementaban los diferentes pasos recomendados en una correcta rutina de ordeño (Ruegg, 2017): despunte en un fondo oscuro, uso de presellador, tiempo adecuado de acción del presellador ( $\geq 30 \mathrm{~s}$ ), limpieza de pezones (material para el secado, ej., papel desechable o tela), uso de sellador y tipo de sellador, si se realizaba sobreordeño y, finalmente, en fincas con ordeño mecánico, si se hacía una desinfección de pezoneras entre vaca y vaca.

Al final de cada ordeño se recolectó una muestra de leche por finca, de cantina (recipiente de aluminio inoxidable para el transporte de un volumen máximo de 401 de leche) o tanque de leche (solo una finca tenía tanque de enfriamiento), para determinar el RCS y el recuento de bacterias mesófilas aerobias. Posterior a la homogenización de la leche de las cantinas o tanque con un agitador previamente desinfectado con alcohol al 70 $\%$ y enjuagado con agua potable, se recolectó una muestra de aproximadamente $40 \mathrm{ml}$ de leche en total, con el 
empleo de una jeringa estéril de $50 \mathrm{ml}$ bajo las condiciones más asépticas posibles (uso de guantes desechables y tapabocas quirúrgico). La muestra se depositó en frascos con conservante (una tableta de $0,1 \mathrm{~g}$ de Azida Sódica, Merck, Darmstadt, Alemania) y se colocaron inmediatamente en una nevera aislante con pilas de hielo, con una temperatura entre 1 y $6{ }^{\circ} \mathrm{C}$. Las muestras se entregaron al Laboratorio de Microbiología Pecuaria y Salud Animal, Área Calidad de Leche de la Corporación Colombia de Investigación Agropecuaria (AGROSAVIA), Centro de Investigación Tibaitatá; Mosquera, Cundinamarca, Colombia, para su procesamiento. El RCS se determinó por citometría de flujo de acuerdo con el método ISO 13366-2. El recuento de bacterias mesófilas aerobias se hizo por citometría de flujo con el equipo BactoScan ${ }^{\mathrm{TM}} \mathrm{FC}+(200 \mathrm{H}$, FOSS, Hilleroed, Dinamarca).

\section{Manejo de datos y análisis estadístico}

La información recolectada a nivel individual y a nivel de hato se registró en Excel ${ }^{\circledR}$ (Microsoft Corp., Redmond, WA) y luego se importó al software estadístico SAS versión 9.4 (Statistical Analysis Systems Institute, 2016). El análisis se realizó en dos niveles, según la unidad del análisis: el animal y el hato. De ese modo, para cada nivel (animal y hato) se estimó la prevalencia de MSC en cada visita; asimismo, se estimó la incidencia acumulada de casos nuevos y casos crónicos de MSC. La prevalencia se estimó como el número de vacas con un RCMT $\geq 1$ dividido entre el número total de vacas muestreadas por visita. Con base en el estado individual de infección de MSC, establecido entre la visita 1 y la 2, y la visita 2 y la 3, se estimó el riesgo (incidencia acumulada) de desarrollar una nueva infección como el número de casos nuevos (vacas recién infectadas) sobre el total de animales en riesgo (vacas sanas en el anterior CMT). Adicionalmente, los casos nuevos, establecidos entre la visita 1 y la 2, se clasificaron como casos crónicos o recuperados según el RCMT de la visita 3. Teniendo en cuenta esto, se estimó el riesgo de desarrollar una infección crónica (incidencia acumulada) como el número de vacas crónicamente infectadas sobre el total de animales en riesgo (vacas recién infectadas) (Cardozo et al., 2015). La estadística descriptiva incluyó porcentajes y medianas, así como el primer y tercer cuartil (rango inter-cuartil [RIC]).

Un modelo de regresión logística mixto (PROC GLIMMIX, SAS) con función de enlace logit y distribución binaria se utilizó para evaluar los factores de riesgo asociados a la presentación de MSC (prevalencia a nivel individual). La variable dependiente de interés fue la presentación de MSC $(0=$ no infectada vs. $1=$ subclínicamente infectada). La variable finca se incluyó como un efecto aleatorio para ajustar el cluster por finca. La variable vaca anidada en finca se incluyó como un componente residual aleatorio utilizando la estructura de varianza-covarianza autorregresiva para ajustar por medidas repetidas de cada vaca. La variable visita se incluyó como un efecto fijo. Para determinar factores asociados con la presentación de un nuevo caso de infección y una infección crónica de MSC se utilizaron modelos de regresión logística mixtos (PROC GLIMMIX, SAS) con función de enlace logit y distribución binaria, y como variable dependiente el estado de infección, con la variable finca como componente aleatorio para ajustar por el cluster por finca.

La prevalencia de MSC a nivel de hato por visita se calculó en SAS (PROC SUMMARY, SAS). La base de datos de prevalencia a nivel de finca se fusionó (por variables finca y visita) con la base de datos sobre factores relacionados con prácticas de ordeño. Se utilizó un modelo lineal generalizado (PROC GLIMMIX, SAS), con función de enlace logit y distribución binomial y la sintaxis events/trials para el análisis de la prevalencia de MSC a nivel de hato (Schabenberger, 2005). La variable dependiente de interés fue el número de vacas con MSC (events) sobre el número total de vacas en ordeño (trials) por finca, por visita. Por lo tanto, el modelo evaluó la probabilidad de una mayor prevalencia de la enfermedad. La variable finca se incluyó como un componente aleatorio utilizando la estructura de varianza-covarianza autorregresiva para ajustar por medidas repetidas. La variable visita se incluyó como un efecto fijo.

La asociación entre la prevalencia de MSC a nivel de hato y los RCS y de bacterias mesófilas en la leche, se evaluó con un modelo lineal generalizado bivariado (PROC GLIMMIX, SAS), utilizando distribución de Poisson. 
La variable finca se incluyó como un componente aleatorio, utilizando la estructura de varianza-covarianza autorregresiva para ajustar por medidas repetidas. Adicionalmente, se evaluaron factores (prácticas de manejo durante el ordeño) asociados con el incremento en el recuento de bacterias mesófilas en cantina.

Para la construcción de cada modelo, primero se analizaron asociaciones entre cada variable dependiente y cada una de las variables independientes. Se utilizó un nivel de significancia, para modelos bivariados, de p<0,2. Posteriormente, se evaluó la existencia de correlación (coeficiente de correlación de Spearman >|0,7l) entre las variables independientes para determinar colinealidad. Si dos variables estaban correlacionadas, solo se incluyó en el análisis multivariado de una de las variables (la de mayor significancia en el análisis bivariado). En este caso, se encontró que la variable limpieza-pezones estuvo correlacionada con las variables uso de presellador $(r=0,72)$ y uso de sellador $(r=0,80)$, por lo que fue omitida del análisis. El modelo multivariado incluyó todas las variables independientes significativas en el bivariado ( $\mathrm{p}<0,2 ;$ Hosmer \& Lemeshow, 2000), y se utilizó eliminación gradual hacia atrás, donde solo permanecieron variables significativas $(\mathrm{p}<0,05)$ o que evidenciaran una tendencia $(\mathrm{p}<0,1)$. Toda variable se consideró confusora (confouder) si al ser eliminada causó un cambio $>20 \%$ en el coeficiente de cualquier otra variable independiente en el modelo (Dohoo et al., 2009); por tanto, permaneció en el modelo final. Se evaluaron interacciones biológicamente posibles entre dos variables y permanecieron en los modelos en caso de ser significativas $(\mathrm{p}<0,05)$.

\section{Resultados}

\section{Características de las fincas}

De las quince fincas seleccionadas, siete se encontraban ubicadas en el municipio de Zipaquirá, cuatro en Cogua, tres en Nemocón y una en Tocancipá. Dos fincas ubicadas en el municipio de Zipaquirá se retiraron del estudio después de la primera visita (una finca se cerró por cuestiones financieras y la otra se cambió de localización por terminación del contrato de arrendamiento de tierra); por lo tanto, para el análisis estas dos fincas solo tenían datos de la visita realizada entre septiembre y octubre de 2019.

La mediana del tamaño del hato fue de veinte vacas en producción por finca (rango: 7 a 45 vacas), así, se categorizaron $47 \%$ de las fincas como medianas (>20 vacas en producción) y $53 \%$ como fincas pequeñas $(\leq 20$ vacas en producción). La raza principal utilizada en las quince fincas fue Holstein ( $82 \%$ de las vacas). La mediana del promedio de edad del hato fue de seis años (RIC: cinco a siete años), la mediana del número de lactancias fue dos (RIC: una a cuatro lactancias), y la mediana de DEP fue 172 días (RIC: 86 a 274 días). En todas las fincas se realizaban dos ordeños diarios. Trece fincas realizaban ordeño mecánico (ocho en un área fija y cinco en el potrero) y dos ordeño manual en el potrero. La producción total diaria de leche por finca (mediana) fue de 4151 día $^{-1}$ (RIC: 250 a $9301 \mathrm{día}^{-1}$ ) para las fincas medianas y de 2101 día $^{-1}$ (RIC: 150 a 2501 día $^{-1}$ ) para las fincas pequeñas $\left(\chi^{2}=\right.$ $5,94 ; \mathrm{p}=0,01)$. La mediana de la producción diaria promedio por vaca por finca fue de 13,51 día $^{-1}$ (RIC: 10,8 a 18 1 día $^{-1}$ ) para las fincas medianas y de 11,71 día $^{-1}$ (RIC: 10 a 13,6 1 día $\left.^{-1}\right)$ para las fincas pequeñas $\left(\chi^{2}=0,65 ; p=0,41\right)$. De manera rutinaria, el CMT se realizaba a todas las vacas en ordeño semanalmente en $13 \%$ de las fincas ( $\mathrm{n}=2 / 15)$, quincenalmente en $13 \%(\mathrm{n}=2 / 15)$ y mensualmente en otro $13 \%$ de las fincas $(\mathrm{n}=2 / 15)$. En $40 \%$ de las fincas $(n=6 / 15)$ el CMT solo se realizaba ocasionalmente a vacas específicas, y en $21 \%$ de las fincas $(n=3 / 15)$ nunca se realizaba esta prueba. 


\section{Características sociodemográficas de los productores y trabajadores}

De los quince productores (propietarios de las fincas), la mayoría eran hombres (93\%; $n=14 / 15)$ y $87 \%$ $(\mathrm{n}=13)$ tenían título universitario. La mediana de la edad fue de 48 años (RIC: 31 a 63 años). En promedio, las fincas contaban con 1,8 trabajadores (rango: 1 a 3 trabajadores), de los cuales $72 \%$ trabajaban tiempo completo, el resto lo hacía medio tiempo. La mediana de la edad de los trabajadores fue 34 años (RIC: 27 a 40 años) y el género predominante fue el masculino (66\%). El nivel educativo preponderante fue primaria completa (37\%), seguido de bachillerato completo (32\%) y técnico (14\%). Catorce (14) productores tenían un trabajador de tiempo completo como encargado general de la finca; solo en una finca el propietario era el mismo encargado.

Durante las tres visitas realizadas se encontró que la mediana del número de ordeñadores por finca fue dos (RIC: uno a tres ordeñadores), que correspondían a un hombre y una mujer en el $56 \%$ de las fincas; en el $34 \%$ el ordeñador era hombre y en el $10 \%$ era mujer. En los Cuadros 1 y 2 se describen la frecuencia de presentación del resto de las variables independientes que incluyen características de las vacas y prácticas de manejo.

Cuadro 1. Estadísticas descriptivas de las variables independientes relacionadas con características de las vacas, \% (n) a en lecherías especializadas. Cundinamarca, Colombia, 2019-2020.

Table 1. Descriptive statistics of the independent variables related to the characteristics of the cows, $\%(n)^{\mathrm{a}}$, on specialized dairies. Cundinamarca, Colombia, 2019-2020.

\begin{tabular}{|c|c|c|c|c|c|}
\hline Variable & Nivel de variable & Visita 1 & Visita 2 & Visita 3 & Todas \\
\hline \multirow[t]{4}{*}{ Lactancia } & 1 & $31(88)$ & $28(85)$ & $27(77)$ & $28(250)$ \\
\hline & 2 & $25(73)$ & $23(68)$ & $22(65)$ & $24(206)$ \\
\hline & 3 & $18(53)$ & $21(62)$ & $23(67)$ & $21(164)$ \\
\hline & $>3$ & $26(74)$ & $28(84)$ & $28(81)$ & $27(239)$ \\
\hline \multirow[t]{3}{*}{ Días en producción } & $<90$ & $25(71)$ & $27(79)$ & $29(82)$ & $27(232)$ \\
\hline & 90 a 180 & $27(77)$ & $27(81)$ & $24(68)$ & $26(226)$ \\
\hline & $>180$ & 48 (139) & $46(136)$ & 47 (136) & $47(411)$ \\
\hline \multirow[t]{2}{*}{ Raza } & Holstein & $84(295)$ & $80(241)$ & $81(239)$ & $82(775)$ \\
\hline & Otra $^{b}$ & $16(55)$ & $20(61)$ & $19(57)$ & $18(173)$ \\
\hline \multirow[t]{2}{*}{ Suciedad de miembros posteriores } & Limpios-ligeramente sucios & $86(291)$ & $74(229)$ & $88(266)$ & $83(786)$ \\
\hline & Muy sucios & $14(46)$ & $26(79)$ & $12(36)$ & $17(161)$ \\
\hline \multirow[t]{2}{*}{ Suciedad de ubre } & Limpia-ligeramente sucia & 94 (317) & $94(290)$ & 98 (296) & $95(903)$ \\
\hline & Muy sucia & $6(20)$ & $6(18)$ & $2(6)$ & $4(44)$ \\
\hline Vacas con mastitis subclínica ${ }^{\mathrm{c}}$ & & $35(122)$ & $53(163)$ & $55(167)$ & $47(452)$ \\
\hline Vacas con mastitis clínica & & $0,3(1)$ & $0,6(2)$ & $1(4)$ & $0,7(7)$ \\
\hline
\end{tabular}

${ }^{\mathrm{a}} \mathrm{El}$ total de vacas no es identico para todas las variables. ${ }^{\mathrm{b}}$ Otras razas puras como Jersey, Ayrshire, Simental y Normado, y cruces con Holstein. ${ }^{c}$ Prevalencia a nivel-vaca. / ${ }^{a}$ The total number of cows is not the same for all variables. ${ }^{b}$ Other pure breeds like Jersey, Ayrshire, Simental and Normand, and crosses with Holstein. ${ }^{\circ}$ Cow-level prevalence. 
Cuadro 2. Estadísticas descriptivas de las variables independientes relacionadas con variables a nivel de hato: prácticas de manejo durante el ordeño en cada finca, \% (n) ${ }^{\mathrm{a}}$, y la mediana (RIC) del recuento de células somáticas y de bacterias mesófilas aerobias de cantina* o tanque de leche en lecherías especializadas. Cundinamarca, Colombia, 2019-2020.

Table 2. Descriptive statistics of the independent variables related to herd-level variables: management practices during milking in each farm, \% (n) ${ }^{\mathrm{a}}$, and the median (ICR) of the somatic cells counts and mesophilic aerobic bacteria counts from canteen* or milk tank on specialized dairies. Cundinamarca, Colombia, 2019-2020.

\begin{tabular}{|c|c|c|c|c|}
\hline Variable & Nivel de variable & Visita 1 & Visita 2 & Visita 3 \\
\hline \multirow[t]{3}{*}{ Número de ordeñadores } & 1 & $47(7)$ & $38(5)$ & $38(5)$ \\
\hline & 2 & $53(8)$ & $62(8)$ & $54(7)$ \\
\hline & 3 & 0 & 0 & $8(1)$ \\
\hline \multirow[t]{3}{*}{ Género de ordeñadores } & Hombre & $40(6)$ & $31(4)$ & $31(4)$ \\
\hline & Mujer $^{\mathrm{b}}$ & $13(2)$ & $8(1)$ & $8(1)$ \\
\hline & Mixto & 47 (7) & $61(8)$ & $61(8)$ \\
\hline \multirow[t]{2}{*}{ Actitud de ordeñador(es $)^{c}$} & Calmada & $80(12)$ & $85(11)$ & $92(12)$ \\
\hline & Afanada & $20(3)$ & $15(2)$ & $8(1)$ \\
\hline \multirow[t]{2}{*}{ Cambio de ordeñador $^{\mathrm{d}}$} & $\mathrm{Si}$ & $7(1)$ & $15(2)$ & $31(4)$ \\
\hline & No & $93(14)$ & $85(11)$ & $69(9)$ \\
\hline \multirow[t]{2}{*}{ Tipo de ordeño } & Manual & $13(2)$ & $15(2)$ & $15(2)$ \\
\hline & Mecánico & $87(13)$ & $85(11)$ & $85(11)$ \\
\hline \multirow[t]{2}{*}{ Sitio de ordeño } & Área fija & $53(8)$ & $46(6)$ & $46(6)$ \\
\hline & Ordeño portátil & $47(7)$ & $54(7)$ & $54(7)$ \\
\hline \multirow[t]{2}{*}{ Presencia techo área preordeño } & $\mathrm{Si}$ & $20(3)$ & $15(2)$ & $15(2)$ \\
\hline & No & $80(12)$ & $85(11)$ & $85(11)$ \\
\hline \multirow[t]{2}{*}{ Presencia de techo en área de ordeño } & $\mathrm{Si}$ & $93(14)$ & $92(12)$ & $92(12)$ \\
\hline & No & $7(1)$ & $8(1)$ & $8(1)$ \\
\hline \multirow[t]{2}{*}{ Condición de limpieza área preordeño } & Aceptable & $53(8)$ & $53(7)$ & $85(11)$ \\
\hline & Embarrada & $47(7)$ & $47(6)$ & $15(2)$ \\
\hline \multirow[t]{2}{*}{ Condición de limpieza área de ordeño } & Aceptable & $93(14)$ & $85(11)$ & $77(10)$ \\
\hline & Sucia & $7(1)$ & $15(2)$ & $23(3)$ \\
\hline \multirow[t]{2}{*}{ Condición salida del ordeño } & Aceptable & $80(12)$ & $85(11)$ & $85(11)$ \\
\hline & Embarrada & $20(3)$ & $15(2)$ & $15(2)$ \\
\hline \multirow[t]{2}{*}{ Realiza segregación ${ }^{\mathrm{f}}$} & $\mathrm{Si}$ & $53(8)$ & $31(4)$ & $38(5)$ \\
\hline & No & $47(7)$ & $69(9)$ & $62(8)$ \\
\hline \multirow[t]{2}{*}{ Uso de guantes } & $\mathrm{Si}$ & $33(5)$ & $31(4)$ & $38(5)$ \\
\hline & No & $67(10)$ & $69(9)$ & $62(8)$ \\
\hline \multirow[t]{2}{*}{ Limpieza de pezones } & $\mathrm{Si}$ & $73(11)$ & $85(11)$ & $77(10)$ \\
\hline & No & $27(4)$ & $15(2)$ & $23(3)$ \\
\hline \multirow[t]{2}{*}{ Realiza despunte } & $\mathrm{Si}$ & $73(11)$ & $77(10)$ & $100(13)$ \\
\hline & No & $27(4)$ & $23(3)$ & 0 \\
\hline \multirow[t]{2}{*}{ Uso de presellador } & $\mathrm{Si}$ & $53(8)$ & $69(9)$ & $77(10)$ \\
\hline & No & $47(7)$ & $31(4)$ & $23(3)$ \\
\hline \multirow[t]{2}{*}{ Tiempo adecuado de presellador } & $\mathrm{Si}$ & $50(4)$ & $33(3)$ & $50(5)$ \\
\hline & No & $50(4)$ & $67(6)$ & $50(5)$ \\
\hline \multirow[t]{2}{*}{ Material para secado de pezones } & Periódico & $91(10)$ & $91(10)$ & $90(9)$ \\
\hline & Otro $^{\mathrm{g}}$ & $9(1)$ & $9(1)$ & $10(1)$ \\
\hline
\end{tabular}


continuación Cuadro $2 \ldots$

\begin{tabular}{|c|c|c|c|c|}
\hline \multirow[t]{2}{*}{ Realiza sobreordeño } & $\mathrm{Si}$ & $60(9)$ & $69(9)$ & $69(9)$ \\
\hline & No & $40(6)$ & $31(4)$ & $31(4)$ \\
\hline \multirow[t]{2}{*}{ Uso de sellador } & $\mathrm{Si}$ & $80(12)$ & $77(10)$ & $85(11)$ \\
\hline & No & $20(3)$ & $23(3)$ & $15(2)$ \\
\hline \multirow[t]{2}{*}{ Tipo de sellador } & De barrera & $17(2)$ & $20(2)$ & $18(2)$ \\
\hline & Convencional & $83(10)$ & $80(8)$ & $82(9)$ \\
\hline \multirow[t]{2}{*}{ Recuento de células somáticas, $\mathrm{x} 10^{3} \mathrm{cel} \mathrm{\textrm {ml } ^ { - 1 }}$} & & 147,1 & 402 & 554,6 \\
\hline & & $(135,7-369,9)$ & $(177,9-574,2)$ & $(237,8-828,4)$ \\
\hline Recueno de bacterias, $\mathrm{x} 10^{3} \mathrm{ufc} \mathrm{ml}^{-1}$ & & $\begin{array}{c}17,1 \\
(5,1-37,7)\end{array}$ & $\begin{array}{c}64,9 \\
(44,9-167,9)\end{array}$ & $\begin{array}{c}37,7 \\
(4,7-74,9)\end{array}$ \\
\hline
\end{tabular}

*Recipiente de aluminio inoxidable para el transporte de un volumen máximo de 401 de leche. ${ }^{a} \mathrm{El}$ total de fincas visitadas no es identico para todas las variables. ${ }^{\mathrm{b}} \mathrm{Cuando}$ era un solo ordeñador haciendo el ordeño. ${ }^{\mathrm{c} D u r a n t e}$ la traída de las vacas al sitio de ordeño. ${ }^{\mathrm{d}} \mathrm{Cambio}$

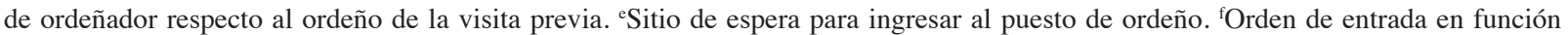
de la presentación de casos de mastitis. ${ }^{g}$ Otro: trapo o papel de cuaderno / *Stainless aluminum container for transporting a maximum volume of 401 of milk. ${ }^{a}$ The total number of farms visited is not the same for all variables. ${ }^{b}$ When it was a single milker doing the milking. ${ }^{c}$ When cows are brought to the milking area. ${ }^{\mathrm{d}}$ Change of milker compared to milking from previous visit. eWaiting site to enter the milking parlor. ${ }^{\mathrm{f}}$ Order of entry depending on the presentation of mastitis cases. ${ }^{g}$ Other: cloth towels or notebook paper.

\section{Prevalencia e incidencia acumulada}

Se realizaron durante las tres visitas un total de 960 CMT a 454 vacas. La prevalencia global de MSC (prevalencia individual) por visita $(1,2$ y 3$)$ fue $35 \%(\mathrm{n}=122 / 350), 53 \%(\mathrm{n}=163 / 308)$ y $55 \%(\mathrm{n}=167 / 302)$, respectivamente. La mediana de la prevalencia en las fincas fue $50 \%$ (RIC: 36 a $61 \%$ ) por visita $(1,2$ y 3$)$ fue 37 \% (RIC: 25 a $52 \%$ ), $51 \%$ (RIC: 40 a $60 \%$ ) y $68 \%$ (RIC: 45 a $76 \%$ ), respectivamente. La prevalencia de MSC a nivel de hato no difirió significativamente entre fincas medianas (45\%; RIC: 30 a $61 \%$ ) y pequeñas (51\%; RIC: 40 a $67 \%)$. La prevalencia de MSC a nivel de hato estuvo directamente asociada con el RCS ( $\beta=0,02 ;$ IC $95 \%=0,006$ a 0,$03 ; \mathrm{p}=0,005)$ y el recuento de bacterias mesófilas $(\beta=0,03$; IC $95 \%=0,007$ a 0,$05 ; \mathrm{p}=0,01)$ (Figura 1 y 2 ).

La mediana de la incidencia acumulada para una nueva infección a nivel de hato, es decir, la proporción de vacas sanas que desarrollan MSC (en un periodo de $56 \mathrm{~d}$ en promedio), fue $42 \%$ (RIC: 30 a $57 \%$ ). La mediana de la incidencia acumulada para una infección crónica, es decir, la proporción de vacas recién infectadas que desarrollan una infección crónica, fue $75 \%$ (RIC: 67 a $100 \%$ ).

\section{Factores asociados con la presentación de mastitis subclínica a nivel del animal}

El modelo final que describe los factores asociados con la presentación de MSC a nivel individual se presenta en el Cuadro 3. Se encontró que a mayor número de lactancias se incrementó el riesgo de presentar MSC, al igual que en vacas en lactancia tardía (>180 DEP), donde el riesgo de presentar MSC fue 3,39 veces más alto en comparación con vacas en lactancia temprana ( $<90 \mathrm{DEP})$. Adicionalmente, se encontró que el realizar sobreordeño y el no utilizar presellador, estuvieron asociados con un mayor riesgo de presentación de MSC (1,96 y 1,74 veces más alto, respectivamente). Por otro lado, el no segregar las vacas con mastitis y el no usar sellador al final del ordeño tendieron a asociarse positivamente con la presentación de casos de MSC. La posibilidad de encontrar vacas con MSC fue más alta en la primera visita realizada a la finca en comparación con las visitas subsecuentes (Cuadro 3). 


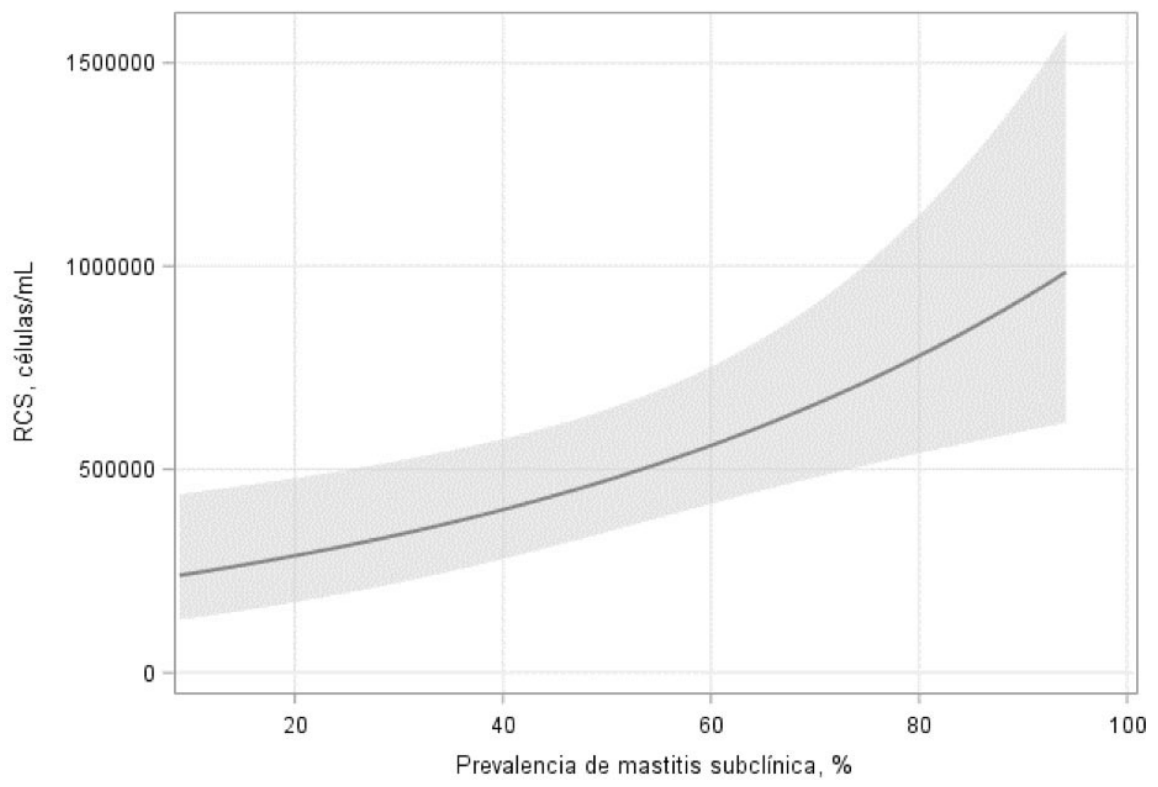

Figura 1. Efecto (IC $95 \%$ ) de la prevalencia de mastitis subclínica a nivel-finca sobre el recuento de células somáticas en cantina (recipiente de aluminio inoxidable para el transporte de un volumen máximo de 401 de leche) o tanque de leche en lecherías especializadas. Cundinamarca, Colombia, 2019-2020.

Figure 1. Effect $(95 \% \mathrm{CI})$ of the prevalence of subclinical mastitis at farm-level on somatic cell count in canteen (stainless aluminum container for transporting a maximum volume of 401 of milk) or milk tank on dairy farms. Cundinamarca, Colombia, 2019-2020.

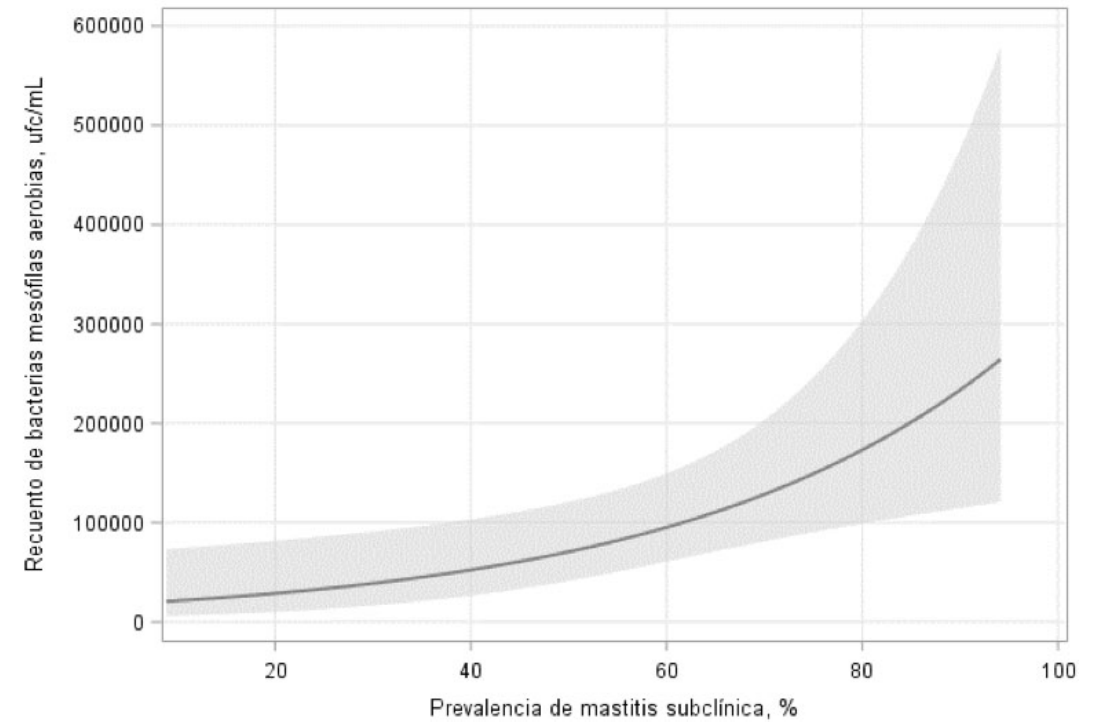

Figura 2. Efecto (IC 95\%) de la prevalencia de mastitis subclínica a nivel-finca sobre el recuento bacterias mesófilas aerobias en cantina (recipiente de aluminio inoxidable para el transporte de un volumen máximo de 401 de leche) o tanque de leche en lecherías especializadas. Cundinamarca, Colombia, 2019-2020.

Figure 2. Effect $(95 \% \mathrm{CI})$ of the prevalence of subclinical mastitis at farm-level on the mesophilic aerobic bacteria count in canteen (stainless aluminum container for transporting a maximum volume of 401 of milk) or milk tank on dairy farms. Cundinamarca, Colombia, 2019-2020. 
Cuadro 3. Modelo de regresión logística mixto final de factores asociados con la probabilidad de presentación de casos positivos a mastitis subclínica (infectada vs. no infectada) a lo largo de las tres visitas realizadas a fincas de lechería especializada. Cundinamarca, Colombia, 2019-2020.

Table 3. Final mixed logistic regression model of factors associated with the probability of presentation of subclinical mastitis positive cases (infected vs. non-infected) throughout the three visits made to specialized dairies. Cundinamarca, Colombia, 2019-2020.

\begin{tabular}{|c|c|c|c|c|c|c|c|c|}
\hline \multirow[t]{2}{*}{ Variable } & \multirow{2}{*}{$\begin{array}{l}\text { Nivel de } \\
\text { variable }\end{array}$} & \multirow[t]{2}{*}{$\beta^{\mathrm{a}}$} & \multirow[t]{2}{*}{$\mathbf{E S}^{\mathbf{b}}$} & \multirow[t]{2}{*}{$\mathbf{O R}^{\mathrm{c}}$} & \multicolumn{2}{|c|}{ IC $95 \%{ }^{d}$} & \multirow[t]{2}{*}{ Valor - p } & \multirow{2}{*}{$\begin{array}{c}\text { Valor - p } \\
\text { general }\end{array}$} \\
\hline & & & & & LCI & LCS & & \\
\hline \multicolumn{9}{|c|}{ Características individuales } \\
\hline \multirow[t]{4}{*}{ Lactancia } & $>3$ & 1,95 & 0,27 & 7,01 & 4,12 & 11,93 & $<0,0001$ & $<0,0001$ \\
\hline & 3 & 1,46 & 0,27 & 4,32 & 2,52 & 7,39 & $<0,0001$ & \\
\hline & 2 & 0,85 & 0,26 & 2,35 & 1,40 & 3,93 & 0,001 & \\
\hline & 1 & Ref. & & & & & & \\
\hline \multirow[t]{3}{*}{ Días en producción } & $>180$ & 1,22 & 0,21 & 3,39 & 2,21 & 5,21 & $<0,0001$ & $<0,0001$ \\
\hline & 90 a 180 & 0,28 & 0,22 & 1,32 & 0,85 & 2,04 & 0,213 & \\
\hline & $<90$ & Ref. & & & & & & \\
\hline \multicolumn{9}{|c|}{ Prácticas durante ordeño } \\
\hline \multirow[t]{2}{*}{ Realizan sobreordeño } & $\mathrm{Si}$ & 0,67 & 0,30 & 1,96 & 1,08 & 3,55 & 0,027 & \\
\hline & No & Ref. & & & & & & \\
\hline \multirow[t]{2}{*}{ Uso de presellador ${ }^{\mathrm{f}}$} & No & 0,56 & 0,28 & 1,74 & 1,01 & 3,03 & 0,048 & \\
\hline & $\mathrm{Si}$ & Ref. & & & & & & \\
\hline \multirow[t]{2}{*}{ Uso de sellador } & No & 0,74 & 0,41 & 2,10 & 0,95 & 4,66 & 0,068 & \\
\hline & $\mathrm{Si}$ & Ref. & & & & & & \\
\hline \multirow[t]{2}{*}{ Segregación ${ }^{\mathrm{h}}$} & No & 0,44 & 0,25 & 1,55 & 0,94 & 2,55 & 0,084 & \\
\hline & $\mathrm{Si}$ & Ref. & & & & & & \\
\hline \multirow[t]{3}{*}{ Visita } & Tercera & 1,03 & 0,21 & 2,79 & 1,84 & 4,26 & $<0,0001$ & $<0,0001$ \\
\hline & Segunda & 0,90 & 0,19 & 2,47 & 1,67 & 3,65 & $<0,0001$ & \\
\hline & Primera & Ref. & & & & & & \\
\hline Intercepto & & $-3,41$ & 0,39 & - & - & - & - & \\
\hline
\end{tabular}

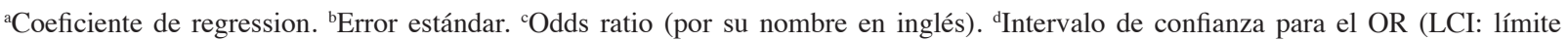
inferior; LCS: límite superior). ${ }^{\circ}$ Categoría de referencia. ${ }^{\mathrm{f}}$ Orden de entrada en función de la presentación de casos de mastitis. ${ }^{g}$ Variable confusora (confounder) para variables sobreordeño y uso de presellador. ${ }^{\text {h} V a r i a b l e ~ c o n f u s o r a ~(c o n f o u n d e r) ~ p a r a ~ v a r i a b l e ~ s o b r e o r d e n ̃ o ~ / ~}$ ${ }^{\mathrm{a}}$ Regression coefficient. ${ }^{\mathrm{b}}$ Standard error. ${ }^{\mathrm{C}}$ Odds ratio. ${ }^{\mathrm{d}}$ Confidence interval for the OR (LCL: lower limit; UCL: upper limit). ${ }^{\mathrm{e}}$ Reference category. ${ }^{\mathrm{f}}$ Order of entry depending on the presentation of cases of mastitis. ${ }^{\mathrm{g}}$ Confounder for over-milking and pre-sealer use variables. ${ }^{\mathrm{h}}$ Confounder variable for over-milking.

Por otro lado, se identificó que el estar en una finca donde se implementa la segregación a la hora de ordeñar (vacas con mastitis se ordeñan al final) y donde se implementa la práctica de usar presellador se asoció con una reducción en el riesgo de presentación de nuevos casos de infección de MSC (Odds ratio - por su nombre en inglés, $\mathrm{OR}=0,37$ y 0,27 , respectivamente; Cuadro 4). Además, el ser una vaca de no más de dos lactancias, estar en lactancia temprana o medía (vs. tardía) y ser ordeñada manualmente fueron factores de protección asociados al riesgo de presentación de nuevos casos de infección de MSC (Cuadro 4). 
Cuadro 4. Modelo de regresión logística mixto final de factores asociados con la presentación de casos nuevos $(\mathrm{n}=103 / 262)$ de mastitis subclínica en vacas en producción en lecherías especializadas. Cundinamarca, Colombia, 2019-2020.

Table 4. Final mixed logistic regression model of factors associated with the presentation of new cases $(\mathrm{n}=103 / 262)$ of subclinical mastitis in lactating cows in specialized dairies. Cundinamarca, Colombia, 2019-2020.

\begin{tabular}{|c|c|c|c|c|c|c|c|c|}
\hline \multirow[b]{2}{*}{ Variables } & \multirow{2}{*}{$\begin{array}{l}\text { Nivel de } \\
\text { variable }\end{array}$} & \multirow[b]{2}{*}{$\beta^{\mathrm{a}}$} & \multirow[b]{2}{*}{$\mathbf{E S}^{\mathbf{b}}$} & \multirow[b]{2}{*}{$\mathbf{O R}^{\mathrm{c}}$} & \multicolumn{2}{|c|}{ IC $95 \%^{d}$} & \multirow[b]{2}{*}{ Valor - $p$} & \multirow{2}{*}{$\begin{array}{l}\text { Valor - } p \\
\text { general }\end{array}$} \\
\hline & & & & & LCI & LCS & & \\
\hline \multirow[t]{4}{*}{ Lactancia } & 1 & $-2,09$ & 0,47 & 0,12 & 0,05 & 0,31 & $<0,001$ & $<0,001$ \\
\hline & 2 & $-0,67$ & 0,47 & 0,29 & 0,12 & 0,76 & 0,011 & \\
\hline & 3 & $-1,21$ & 0,49 & 0,51 & 0,19 & 1,34 & 0,173 & \\
\hline & $>3$ & Ref. $^{\text {e }}$ & & & & & & \\
\hline \multirow[t]{3}{*}{ Días en producción } & $<90$ & $-1,17$ & 0,48 & 0,32 & 0,12 & 0,86 & 0,015 & 0,001 \\
\hline & 90 a 180 & $-1,18$ & 0,34 & 0,29 & 0,14 & 0,59 & $<0,001$ & \\
\hline & $>180$ & Ref. & & & & & & \\
\hline \multirow[t]{2}{*}{ Segregación ${ }^{\mathrm{f}}$} & $\mathrm{Si}$ & $-0,99$ & 0,35 & 0,37 & 0,18 & 0,74 & 0,005 & \\
\hline & No & Ref. & & & & & & \\
\hline \multirow[t]{2}{*}{ Uso de presellador } & $\mathrm{Si}$ & $-1,30$ & 0,45 & 0,27 & 0,11 & 0,67 & 0,004 & \\
\hline & No & Ref. & & & & & & \\
\hline \multirow[t]{2}{*}{ Tipo de ordeño } & Manual & $-0,98$ & 0,52 & 0,38 & 0,14 & 1,04 & 0,059 & \\
\hline & Mecánico & Ref. & & & & & & \\
\hline Intercepto & & 3,03 & 0,59 & - & - & - & - & \\
\hline
\end{tabular}

${ }^{a}$ Coeficiente de regresión. ${ }^{b}$ Error estándar. ${ }^{\mathrm{c} O d d s}$ ratio. ${ }^{\mathrm{d} I n t e r v a l o ~ d e ~ c o n f i a n z a ~ p a r a ~ e l ~ O R ~(L C I: ~ l i ́ m i t e ~ i n f e r i o r ; ~ L C S: ~ l i ́ m i t e ~ s u p e r i o r) . ~}$

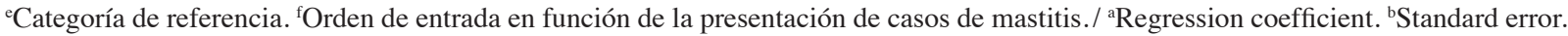
${ }^{\mathrm{C}}$ Odds ratio. ${ }^{\mathrm{d}}$ Confidence interval for the OR (LCL: lower limit; UCL: upper limit). ${ }^{\mathrm{e}}$ Reference category. ${ }^{\mathrm{f}}$ Order of entry depending on the presentation of cases of mastitis.

Para el riesgo de presentación de casos crónicos de infección de MSC solo se encontraron resultados significativos en el análisis bivariado $(\mathrm{p}<0,2)$, que reveló que las variables limpieza de pezones y uso de presellador fueron factores de protección. En el análisis multivariado no se evidenció significancia de ninguna variable independiente, posiblemente debido al tamaño de muestra (45 de las 65 vacas que presentaron una infección nueva en la visita 2 estuvieron presentes en la prueba CMT de la visita 3, de estas 45 vacas, 34 vacas presentaron una infección crónica en la visita 3).

\section{Factores asociados con la presentación de mastitis subclínica a nivel de hato y con recuentos de bacterias en leche}

El modelo final que describe los factores asociados con la probabilidad de una mayor prevalencia de MSC a nivel-finca están resumidos en el Cuadro 5. No utilizar presellador y no realizar segregación a la hora de ordeñar estuvieron asociados, directamente, con una mayor prevalencia de MSC. Específicamente, el no realizar el presellado y el no segregar generaron un incremento de entre 22 y 23 puntos porcentuales en la prevalencia de MSC.

En cuanto al recuento de bacterias mesófilas en leche (de cantina o tanque de leche), se encontró una asociación positiva con la prevalencia de vacas con ubres sucias, no dejar actuar el presellador el tiempo adecuado (por menos de 30 s), tener más de un ordeñador, no segregar y el cambio de ordeñadores con relación a la visita previa (Cuadro 6). 
Cuadro 5. Modelo lineal generalizado final de factores asociados la probabilidad de una mayor prevalencia de mastitis subclínica a nivel-finca en lecherías especializadas. Cundinamarca, Colombia, 2019-2020.

Table 5. Final generalized linear regression model of factors associated with the odds of a higher prevalence of subclinical mastitis at the farm level in specialized dairies. Cundinamarca, Colombia, 2019-2020.

\begin{tabular}{|c|c|c|c|c|c|c|c|c|c|}
\hline \multirow[b]{2}{*}{ Variable } & \multirow{2}{*}{$\begin{array}{l}\text { Nivel de } \\
\text { variable }\end{array}$} & \multirow[b]{2}{*}{$\beta^{\mathbf{a}}$} & \multirow[b]{2}{*}{$\mathbf{E S}^{\mathbf{b}}$} & \multirow[b]{2}{*}{$\mathbf{O R}^{\mathrm{c}}$} & \multicolumn{2}{|c|}{ IC $95 \%{ }^{d}$} & \multirow[b]{2}{*}{ Valor - p } & \multirow{2}{*}{$\begin{array}{c}\text { Valor - p } \\
\text { general }\end{array}$} & \multirow{2}{*}{$\begin{array}{c}\mathbf{P A}^{\mathrm{e}}, \% \text { (IC } \\
95 \%)\end{array}$} \\
\hline & & & & & LCI & LCS & & & \\
\hline \multirow[t]{2}{*}{ Segregación ${ }^{\mathrm{f}}$} & No & 0,88 & 0,23 & 2,42 & 1,17 & 5,03 & 0,031 & & $61(49-72)$ \\
\hline & $\mathrm{Si}$ & Ref.g & & & & & & & $39(25-55)$ \\
\hline \multirow[t]{2}{*}{ Uso de presellador } & No & 0,91 & 0,26 & 2,50 & 0,81 & 7,68 & 0,073 & & $61(37-81)$ \\
\hline & $\mathrm{Si}$ & Ref. & & & & & & & $38(26-53)$ \\
\hline \multirow[t]{3}{*}{ Visita } & Tercera & 1,04 & 0,25 & 2,84 & 1,36 & 3,54 & $<0,001$ & 0,001 & $61(50-70)$ \\
\hline & Segunda & 0,78 & 0,23 & 2,19 & 2,67 & 4,83 & 0,002 & & $54(44-64)$ \\
\hline & Primera & Ref. & & & & & & & $35(27-44)$ \\
\hline Intercepto & & $-1,51$ & 0,24 & - & - & - & - & - & - \\
\hline
\end{tabular}

${ }^{a}$ Coeficiente de regresión. ${ }^{b}$ Error estándar. ${ }^{\mathrm{c}}$ Odds ratio. ${ }^{\mathrm{d} I n t e r v a l o ~ d e ~ c o n f i a n z a ~ p a r a ~ e l ~ O R ~(L C I: ~ l i ́ m i t e ~ i n f e r i o r ; ~ L C S: ~ l i ́ m i t e ~ s u p e r i o r) . ~}$ ePrevalencia ajustada. ${ }^{\mathrm{f}}$ Orden de entrada en función de la presentación de casos de mastitis. ${ }^{\mathrm{g}}$ Categoría de referencia / aRegression coefficient. ${ }^{\mathrm{b}}$ Standard error. ${ }^{\mathrm{C}}$ Odds ratio. ${ }^{\mathrm{d}}$ Confidence interval for the OR (LCL: lower limit; UCL: upper limit). ${ }^{\mathrm{e}}$ Adjusted Prevalence. ${ }^{\mathrm{f}}$ Entry order based on presentation of mastitis cases. ${ }^{\circ}$ Reference category.

Cuadro 6. Modelo lineal generalizado con distribución Poisson de factores asociados con el recuento de bacterias mesófilas a nivel finca en lecherías especializadas. Cundinamarca, Colombia, 2019-2020.

Table 6. Generalized linear model with Poisson distribution of factors associated with the count of mesophilic bacteria at the farm level in specialized dairies. Cundinamarca, Colombia, 2019-2020.

\begin{tabular}{|c|c|c|c|c|c|c|}
\hline \multirow[b]{2}{*}{ Variable } & \multirow[b]{2}{*}{ Nivel de variable } & \multirow[b]{2}{*}{$\beta^{\mathbf{a}}$} & \multirow[b]{2}{*}{$\mathbf{E S}^{\mathbf{b}}$} & \multicolumn{2}{|c|}{ IC $95 \%{ }^{c}$} & \multirow[b]{2}{*}{ Valor - p } \\
\hline & & & & LCI & LCS & \\
\hline Prevalencia ubres sucias, $\%$ & & 0,12 & 0,03 & 0,05 & 0,18 & 0,003 \\
\hline \multirow[t]{2}{*}{ Número de ordeñadores } & $>1$ ordeñador & 1,11 & 0,42 & 0,15 & 2,07 & 0,028 \\
\hline & 1 ordeñador & Ref. & & & & \\
\hline \multirow[t]{2}{*}{ Segregación ${ }^{\mathrm{d}, \mathrm{e}}$} & No & 0,83 & 0,35 & $-0,28$ & 1,94 & 0,098 \\
\hline & $\mathrm{Si}$ & Ref. & & & & \\
\hline \multirow[t]{2}{*}{ Cambio de ordeñador } & $\mathrm{Si}$ & 1,14 & 0,28 & $-0,06$ & 2,35 & 0,055 \\
\hline & No & Ref. & & & & \\
\hline \multirow[t]{2}{*}{ Tiempo de acción presellador } & Inadecuado $(<30 \mathrm{seg})$ & 1,62 & 0,43 & 0,43 & 2,81 & 0,019 \\
\hline & Adecuado ( $\geq 30 \mathrm{seg}$ ) & Ref. & & & & \\
\hline Intercepto & & 7,74 & 0,62 & - & - & - \\
\hline
\end{tabular}

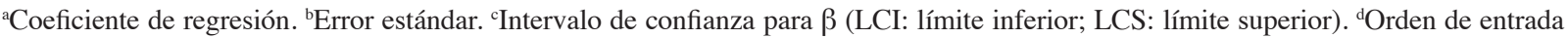
en función de la presentación de casos de mastitis. ${ }^{e}$ Variable de confusión para variables número y cambio de ordeñadores y tiempo de acción del presellador / ${ }^{a}$ Regression coefficient. ${ }^{b}$ Standard error. ${ }^{\mathrm{c} C o n f i d e n c e ~ i n t e r v a l ~ f o r ~} \beta$ (LCL: lower limit; UCL: upper limit). ${ }^{\mathrm{d}}$ Order of entry depending on the presentation of mastitis cases. ${ }^{\circ}$ Confounder variable for variables number and change of milkers and pre-sealer action time. 


\section{Discusión}

Este estudio observacional y analítico es uno de los primeros en proporcionar información sobre factores de riesgo asociados a la presentación de mastitis subclínica (MSC) bovina en la cuenca lechera cundinamarquesa colombiana. Particularmente, la lactancia, los días en producción, la segregación, el presellado y el sobreordeño fueron factores claves, ya que se asociaron con la presentación de casos nuevos y casos prevalentes de MSC. Estos resultados destacan las prácticas de manejo que podrían mejorarse para tener una mejor salud de ubre y producir leche de mejor calidad. Es importante tener en cuenta que al evaluar la representatividad de las fincas participantes, se encontró una similitud con datos poblacionales de lecherías especializadas en Colombia (ej. tamaño promedio del hato: en el presente estudio $=20$ vacas, a nivel nacional $=67 \%$ de los predios ganaderos tienen menos de 25 vacas; producción promedio de leche diaria por finca: en el presente estudio $=312$ 1, a nivel nacional =292 1 (Federación Colombiana de Ganaderos, 2018). Por lo cual, los resultados del presente estudio pueden ser extrapolados no solo a otras lecherías en Cundinamarca, sino a la mayoría de las lecherías especializadas en el trópico alto colombiano (30 mil aproximadamente) y a sistemas similares en otros países tropicales.

Durante el periodo de estudio se encontró que la mitad de las vacas en producción por finca fueron positivas a MSC (mediana de la prevalencia) a lo largo de las tres visitas. Los resultados se encuentran dentro de los valores estimados en la misma zona (55\%) por Romero et al. (2018) y en otras cuencas lecheras colombianas como Norte de Santander y Antioquia, donde se encontraron prevalencias de $54 \%$ y $40 \%$, respectivamente (Mendoza et al., 2017; Ramírez-Vásquez et al., 2011). Adicionalmente, la prevalencia estimada en este estudio fue similar a reportes en sistemas semejantes en otros países de la región como Venezuela (58 \%; Castillo et al., 2009) y Brasil (53 \%; da Costa-Ribeiro et al., 2016), e incluso menor a reportes en Perú (65 \%; Santivañez-Ballón et al., 2013).

La prevalencia en este estudio difirió significativamente entre las visitas realizadas a las fincas, siendo mayor en las visitas $2(51 \%)$ y $3(68 \%)$ en comparación con la primera $(37 \%)$. Las diferencias entre la visita 1 y la 2 pudieron deberse a factores climáticos como el aumento en la precipitación en la visita 2 (precipitación acumulada mensual, visita 1: $115 \mathrm{~mm}$, visita 2: $165 \mathrm{~mm}$; Instituto de Hidrología, Meteorología y Estudios Ambientales [IDEAM], 2020a), sabiendo que durante épocas más lluviosas la presentación de mastitis aumenta (Nóbrega \& Langoni, 2011). La hipótesis fue que las diferencias entre la visita 1 y la 3 y entre la visita 2 y la 3 se pudieron presentar indirectamente debido primero, a la presentación del fenómeno de heladas ("ocurrencia de una temperatura igual o menor a $0^{\circ} \mathrm{C}$ a un nivel de $2 \mathrm{~m}$ sobre el nivel del suelo"; González-Gómez \& Torres-Triana, 2012) durante la visita 3 (temperatura mínima, septiembre-octubre 2019: $5{ }^{\circ} \mathrm{C}$; noviembre-diciembre: $6{ }^{\circ} \mathrm{C}$; enerofebrero 2020: $-3{ }^{\circ} \mathrm{C}$ (IDEAM, 2020b), lo que generó una baja disponibilidad de alimento en las fincas del presente estudio y una pérdida de condición corporal en las vacas. El balance energético negativo en vacas en producción se asoció con una mala salud de la ubre (Van Straten et al., 2009). Segundo, pudo deberse a factores circunstanciales inherentes a la época entre visitas como el cambio de ordeñadores por temas de reemplazos y vacaciones de fin de año del personal. Este último punto se relaciona con la posible falta de continuidad en la rutina de ordeño durante esta época del año, ya que se sabe que el no ser consistente puede traer como consecuencia una reducción no solo en la producción de leche sino en la calidad, y un incremento en la presentación de mastitis (Stup, 2002).

Al observar la incidencia acumulada de desarrollar una nueva infección de MSC (42\%) y la probabilidad que estos nuevos casos se vuelvan crónicos (75\%), se puede entender el por qué la prevalencia de MSC (50\%) fue más alta que la incidencia, ya que es una enfermedad crónica (Dohoo et al., 2009). Por lo tanto, es importante identificar qué factores se asocian no solo con adquirir la infección (incidencia y factores claves para prevención), sino también con tenerla (prevalencia y factores claves para control).

En cuanto a factores relacionados con características individuales de las vacas, en este estudio se identificó que animales de una o dos lactancias tuvieron un menor riesgo de presentar un nuevo caso de MSC en comparación con vacas de más de tres lactancias ( $\mathrm{OR}=0,12$ y 0,29, respectivamente; Cuadro 4). Estos resultados respaldan los 
hallazgos de Cardozo et al. (2015), quienes encontraron que vacas primíparas tenían un menor riesgo $(\mathrm{OR}=0,58)$ de presentar un nuevo caso de MSC respecto a vacas de más de cuatro lactancias; igualmente, respaldan los hallazgos referentes a la presentación de casos nuevos de mastitis clínica, donde Pinzón-Sánchez \& Ruegg (2011) encontraron que vacas primíparas tuvieron un menor riesgo $(\mathrm{OR}=0,07)$ de recurrencia respecto a vacas de $>3$ lactancias.

Entre más lactancias tiene una vaca, mayor es su susceptibilidad a infecciones intramamarias, mayor es el tiempo que está expuesta a patógenos y, por tanto, mayor es su respuesta inmune a estos (Ruegg \& Pantoja, 2013). Adicionalmente, en este estudio se identificó que vacas con $\leq 90$ DEP y entre 90 y 180 DEP, tuvieron un menor riesgo de presentar un nuevo caso de MSC en comparación con animales con $>180$ DEP (OR=0,32 y 0,29, respectivamente; Cuadro 4). Similarmente, en hatos lecheros en Etiopía se ha evidenciado la misma asociación, donde vacas en lactancia temprana $(<90 \mathrm{DEP})$ fueron menos propensas a presentar MSC $(\mathrm{OR}=0,41)$ que vacas con más de 180 DEP (Tolosa et al., 2013). En ese sentido, el presente estudio mostró que el número de lactancias y DEP se asociaron positivamente con la probabilidad de una vaca de tener MSC (Cuadro 3), lo cual fue similar a hallazgos de otros estudios, donde se ha evidenciado que vacas multíparas son 2,5 veces más susceptibles a tener MSC que vacas primíparas (Santivañez-Ballón et al., 2013; Baptiste-Ndahetuye et al., 2019); además, vacas con >150 DEP tienen un riesgo de 1,9 a 2,6 veces mayor de padecer la infección (Mekonnen et al., 2017).

En cuanto a factores de manejo durante el ordeño, en este estudio se determinó que las prácticas de segregar animales infectados (orden de ordeño), presellar y evitar el sobreordeño, son claves para reducir el riesgo de adquirir y de tener MSC. Se identificó que las vacas en fincas donde se implementaba la práctica de ordeñar vacas con mastitis al final, tuvieron un riesgo menor de presentar un nuevo caso de MSC ( $O R=0,37)$, lo cual es semejante a los hallazgos de Cardozo et al. (2015), donde el segregar animales fue un factor de protección para la presentación de nuevos casos de MSC $(\mathrm{OR}=0,66)$. Por el contrario, en las fincas del presente estudio donde no se tenía esta práctica establecida, el riesgo de una vaca de tener MSC fue mayor $(\mathrm{OR}=1,5)$, al igual que la probabilidad de una mayor prevalencia de MSC a nivel hato se incrementó (22\% más alta). Similarmente, en hatos portugueses se evidenció la misma asociación, donde el no segregar animales infectados durante el ordeño estuvo asociado positivamente con un incremento de $21 \%$ en la prevalencia de mastitis (Azevedo et al., 2016).

Se encontró que vacas en fincas donde se usa el presellado de pezones con una solución desinfectante como parte de la preparación de la ubre para el ordeño, tuvieron un riesgo menor de presentar un nuevo caso de MSC $(\mathrm{OR}=0,27)$. Por el contrario, fincas donde no se utilizaba el presellador, la probabilidad de una vaca de tener MSC fue mayor $(\mathrm{OR}=1,7)$, al igual que la probabilidad de una mayor prevalencia de $\mathrm{MSC}$ a nivel de hato tendió a incrementar (23\% más alta). Los hallazgos del presente estudio corroboran resultados de investigaciones previas, donde la aplicación de presellador ( $v s$. no aplicación de presellador; ambos tratamientos incluyeron la aplicación del sellado final) redujo entre un $34 \%$ y $54 \%$ la presentación de nuevos casos de infecciones intramamarias (Oliver et al., 1993; Pankey et al., 1987, respectivamente). Este tipo de estudios han demostrado la importancia del acompañamiento del sellado con el presellado, aunque su adopción es aún limitada. Por ejemplo, tanto en Canadá como en Colombia, el uso del presellador es menos común o nulo en comparación al uso del sellador [(Canadá: 97 vs. $65 \%$ (Belage et al., 2017a) y Colombia: 0 vs $30 \%$ (Silva-Pulido et al., 2014)].

El sobreordeño incrementó la probabilidad de una vaca de tener MSC (OR=1,96; Cuadro 3). Este resultado respalda los hallazgos de la revisión sistemática realizada por Dufour et al. (2011), donde se identificó el no tener pezoneras de remoción automática como una práctica de manejo consistentemente correlacionada con altos RCS. El uso de este tipo de pezoneras es clave para evitar el sobreordeño, el cual se ha demostrado genera daño de los pezones a corto y largo plazo (Edwards et al., 2013). Sin embargo, ninguna finca en el presente estudio tenía este tipo de pezoneras; en Canadá, por ejemplo, $20 \%$ de productores en un estudio representativo de los sistemas lecheros no tenía este tipo de equipos (Belage et al., 2017a) y, aunque no encontraron una diferencia significativa en el RCS entre usuarios y no usuarios de pezoneras automáticas, Belage et al. (2017a) cuestionaron la falta de adopción de este tipo de prácticas, las cuales han demostrado ampliamente sus beneficios, y enfatizan su importancia para 
reducir el sobreordeño y el daño de los pezones. Sumado a este hallazgo, se identificó que el ordeñar manualmente fue un factor de protección para la presentación de nuevos casos de MSC ( $\mathrm{OR}=0,38)$. Contrariamente, en fincas lecheras en Antioquia, Colombia, el ordeño manual incrementó el riesgo de presentar una infección intramamaria causada por Streptococcus agalactiae $(\mathrm{OR}=5,37)$ frente a ordeño mecánico, lo que indica que probablemente se debió al contagio de vacas sanas a través de las manos contaminadas de los ordeñadores (Ramírez et al., 2014). La hipótesis para este hallazgo es que, en las fincas del presente estudio, el ordeño manual se realizó en condiciones aparentemente limpias frente a un ordeño mecánico que en la mayoría de las fincas se realizaba con un equipo que no recibía la correcta limpieza y desinfección pre y post ordeño. Este aspecto de la limpieza adecuada del equipo de ordeño no se evaluó objetivamente en este estudio, por eso no se incluyó como una variable.

Otro hallazgo del presente estudio fue que la prevalencia a nivel de hato estuvo positivamente asociada con el RCS y con el recuento de bacterias en la leche de cantina (o de tanque), lo que indica que los niveles altos de MSC en la finca afectaron la calidad higiénica de la leche para la venta. Este resultado es congruente con otros estudios que evidenciaron una asociación entre el RCS y la prevalencia de mastitis en general (Emanuelson \& Funke, 1991) y de MSC causada por Streptococcus agalactiae y Staphylococcus aureus (Olde-Riekerink et al., 2006). Los resultados respecto al recuento de bacterias y la afectación de la calidad higiénica de la leche corroboran lo encontrado por Rodrigues et al. (2005), quienes en un estudio en hatos lecheros de Wisconsin, USA, obtuvieron una asociación positiva, no solo entre la prevalencia de MSC y RSC, sino también entre RCS y recuentos totales de bacterias, con aislamientos principalmente de patógenos contagiosos como Staphylococcus aureus (Rodrigues et al., 2005). Sumado a esto, productores de fincas con RCS más elevados fueron a su vez los que reportaron la más baja tasa de consulta a profesionales veterinarios, lo que se ha visto previamente ligado a la falta de adopción de buenas prácticas de ordeño (Rodrigues et al., 2005), lo cual reconfirma la importancia de una correcta asesoría para corregir las prácticas de ordeño y reducir el impacto negativo en la calidad de la leche.

En el presente estudio se identificó como factores de riesgo asociados significativamente con un incremento en el recuento de bacterias en leche de cantina (o de tanque de leche) a la prevalencia de vacas con la ubre sucia, el no dejar actuar el presellador por lo menos $30 \mathrm{~s}$, el tener más de un ordeñador y al cambio de ordeñadores respecto a la visita previa (Cuadro 6). Los resultados respecto a la suciedad en las vacas y al uso inadecuado del presellador corroboran lo encontrado en estudios como el realizado en Canadá por Elmoslemany et al. (2009), donde se evidenció que el recuento de bacterias en tanque fue más alto cuando las ubres estaban sucias y cuando no se utilizaba presellador (igualmente comprobado en un estudio en Pensilvania, USA; Jayarao et al., 2004). Indirectamente, un estudio irlandés ratificó la importancia de la limpieza de los animales al encontrar que el peluquear la borla de la cola de las vacas al menos una vez al año estuvo asociado con un recuento bajo de bacterias en tanque (Kelly at al., 2009).

Respecto al uso inadecuado del sellador, los resultados del presente estudio se asemejan a lo evidenciado en un estudio canadiense sobre adopción y consistencia de prácticas para la preparación de la ubre para el ordeño (Belage et al., 2017b). En ese estudio se encontró que la estabulación libre con cubículos (free-stall) fue un factor asociado al uso adecuado del presellador (dejarlo actuar más de 30 s), en comparación con estabulación fija (tie-stall). Los autores atribuyeron esta diferencia a factores inherentes a la rutina de ordeño de cada sistema, ya que en las fincas de estabulación libre cada paso de la rutina se aplica a varias vacas a la vez antes de pasar al siguiente paso hasta la colocación de las pezoneras. Mientras que en las fincas de estabulación fija hay más variación en la forma en que cada vaca es preparada para el ordeño, ya que es casi individual y es dependiente del movimiento de la unidad de una vaca a otra. Este último sistema de ordeño se asemeja a los sistemas implementados en algunas de las fincas del presente proyecto, donde el número de unidades de ordeño y puestos de ordeño son solo dos, lo que hace que los tiempos de preparación de cada vaca no sean constantes y pueda haber un mayor margen de error en el manejo de tiempos de acción de los desinfectantes. 
En el presente trabajo, el tener más de un ordeñador o cambiar de ordeñador (con respecto a la visita previa), se asoció con un mayor recuento de bacterias en la leche. Se ha reportado que entre más personas involucradas en el proceso de ordeño, menor es la homogeneidad entre los ordeñadores en los pasos para la óptima preparación de la ubre; entendiendo que esta estandarización entre ordeñadores es esencial para la prevención de la mastitis (Belage et al., 2017b).

\section{Conclusiones}

Este estudio identificó al número de lactancias, los días en producción (DEP), el no segregar, el no usar presellador y el realizar sobreordeño, como factores que se asociaron con adquirir y tener mastitis subclínica (MSC), por lo tanto, son factores claves para tener en cuenta en medidas de prevención y control de esta enfermedad.

Hubo una relación entre la alta prevalencia de MSC y los altos recuentos de células somáticas (RCS) y recuentos de bacterias en la leche de cantina. Estos últimos también se vieron afectados por la alta prevalencia de ubre sucias, el inadecuado uso del presellador y la posible falta de consistencia en los pasos de la rutina de ordeño por parte de los ordeñadores.

Los niveles de MSC encontrados son de importante magnitud y pueden afectar directamente la rentabilidad del negocio. Los altos recuentos bacterianos en la leche de estos sistemas pueden poner en riesgo la salud de las personas si consumen leche no pasteurizada. Se recomienda para las lecherías especializadas en el trópico alto colombiano la implementación de una rutina de ordeño sistemática y constante; además de la implementación un programa de monitoreo de mastitis, donde se evalúen RCS individuales o se realice CMT al menos una vez al mes para dar especial atención a los casos crónicos, determinar el orden de entrada al ordeño y tomar decisiones de descarte de animales.

Campañas educativas directas con los productores y trabajadores en el campo, sobre programas generales de salud de hato y específicamente de salud de la ubre, se hacen necesarias y urgentes para corregir los problemas detectados.

\section{Agradecimientos}

Los autores desean agradecer al Ministerio de Agricultura y Desarrollo Rural de Colombia (Bogotá, Colombia) y a la Corporación Colombiana de Investigación Agropecuaria (AGROSAVIA) Mosquera, Colombia, por financiar esta investigación. La participación del primer autor la financió el Ministerio de Ciencia, Tecnología e Innovación (Minciencias) Bogotá, Colombia, bajo la modalidad de estancias postdoctorales. Se agradece a Andrea Flórez Salazar, Diego A. Velasco Acosta y Rodrigo R. Rocha Sanabria por su colaboración en algunas de las visitas para la recolección de datos. Los autores agradecen al Comité de Ganaderos Área 5 (Zipaquirá, Colombia) y a los productores por su participación y disponibilidad de tiempo durante las visitas realizadas.

\section{Referencias}

Adkins, P. R. F., \& Middleton, J. R. (2018). Methods for diagnosing mastitis. Veterinary Clinics of North America, 34(3), 479491. https://doi.org/10.1016/j.cvfa.2018.07.003

Aghamohammadi, M., Haine, D., Kelton, D. F., Barkema, H. W., Hogeveen, H., Keefe, G. P., \& Dufour, S. (2018). Herdlevel mastitis-associated costs on Canadian dairy farms. Frontiers in Veterinary Science, 5, Article 100. https://doi. org/10.3389/fvets. 2018.00100 
Azevedo C., Pacheco, D., Soares, L., Romão, R., Moitoso, M., Maldonado, J., Guix, R., \& Simões, J. (2016). Prevalence of contagious and environmental mastitis-causing bacteria in bulk tank milk and its relationships with milking practices of dairy cattle herds in São Miguel Island (Azores). Tropical Animal Health and Production, 48, 451-459. https://doi. org/10.1007/s11250-015-0973-6

Baptiste-Ndahetuye, J., Persson, Y., Nyman, A. K., Tukei, M., Ongol, M. P., \& Båge, R. (2019). Aetiology and prevalence of subclinical mastitis in dairy herds in peri-urban areas of Kigali in Rwanda. Tropical Animal Health and Production, 51, 2037-2044. https://doi.org/10.1007/s11250-019-01905-2

Belage, E., Dufour, S., Bauman, C., Jones-Bitton, A., \& Kelton, D. F. (2017a). The Canadian National Dairy Study 2015-Adoption of milking practices in Canadian dairy herds. Journal of Dairy Science, 100(5), 3839-3849. https:// doi.org/10.3168/jds.2016-12187

Belage, E., Dufour, S., Shock, D. A., Jones-Bitton, A., \& Kelton, D. F. (2017b). Adoption and consistency of application of premilking preparation in Ontario dairy herds. Journal of Dairy Science, 100, 3902-3911. https://doi.org/10.3168/ jds.2016-11698

Blowey, R. W, \& Edmondson, P. (2010). Mastitis control in dairy herds (2 ${ }^{\text {nd }}$ Ed.). CAB International.

Cardozo, L., Thaler-Neto, A., Souza, G. N., Picinin, L. A. C., Felipus, N. C., Reche, N. M. L., Schmidt, F. A., Werncke, D., \& Simon, E. E. (2015). Risk factors for the occurrence of new and chronic cases of subclinical mastitis in dairy herds in southern Brazil. Journal of Dairy Science, 98, 7675-7685. http://dx.doi.org/10.3168/jds.2014-8913

Castillo, M., Suniaga, J., Rojas, G., Hernández, J., Caamaño, J., Urbina, A., \& Tovar, L. (2009). Estudio de prevalencia de mastitis subclínica en la zona alta del estado Mérida. Agronomía Andina, 16, 39-48.

da Costa-Ribeiro, A. B., Sifuentes dos Santos, J., Zanol, D., Leme Lombarde, L. N., Bruzaroski, S. R., Ludovico, A., \& Walter de Santana, E. H. (2016). Evaluation of an electrical conductivity portable device as an alternative for subclinical mastitis detection. Revista de Salud Animal, 38(2), 131-135.

Departamento Administrativo Nacional de Estadística. (2018). Censo Nacional de Población y Vivienda 2018 - Colombia. https://www.dane.gov.co/index.php/estadisticas-por-tema/demografia-y-poblacion/censo-nacional-de-poblacion-yvivenda-2018

Dohoo, I., Martin, Q., \& Stryhn, H. (2009). Veterinary epidemiologic research (2 ${ }^{\text {nd }}$ Ed.). VER Inc.

Dufour, S., Fréchette, A., Barkema, H. W., Mussell, A., \& Scholl, D. T. (2011). Invited review: Effect of udder health management practices on herd somatic cell count. Journal of Dairy Science, 94, 563-579. https://doi.org/10.3168/jds.2010-3715

Edwards, J., O’Brien, B., Lopez-Villalobos, N., \& Jago, J. (2013). Overmilking causes deterioration in teat-end condition of dairy cows in late lactation. Journal of Dairy Research, 80(3), 344-348. https://doi.org/10.1017/S0022029913000307

Elmoslemany, A. M., Keefe, G. P., Dohoo, I. R., \& Jayarao, B. M. (2009). Risk factors for bacteriological quality of bulk tank milk in Prince Edward Island dairy herds. Part 2: Bacteria count-specific risk factors. Journal of Dairy Science, 92 , 2644-2652. https://doi.org/10.3168/jds.2008-1813

Emanuelson, U. L. F., \& Funke, H. (1991). Effect of Milk Yield on Relationship Between Bulk Milk Somatic Cell Count and Prevalence of Mastitis. Journal of Dairy Science, 74, 2479-2483. https://doi.org/10.3168/jds.S0022-032(91)78424-5

Federación Colombiana de Ganaderos. (2018). Ganadería colombiana hoja de ruta 2018 - 2022. http://static.fedegan.org.co.s3. amazonaws.com/publicaciones/Hoja_de_ruta_Fedegan.pdf 
Gobernación de Cundinamarca. (2018). Municipios. http://www.cundinamarca.gov.co/Home/Cundinamarca.gc/ascundi_ municipioscontenidos/ccundi_municipios

González-Gómez, O. C., \& Torres-Triana, C. F. (2012). Actualización técnica heladas. Instituto de Hidrología, Meteorología y Estudios Ambientales (IDEAM). http://www.ideam.gov.co/documents/21021/21147/Documento+FINAL+actualizaci on+nota+tecnica+heladas.pdf/e10a0183-62e6-410a-8e96-7e0739f6f06b

Hosmer, D. W., \& Lemeshow, S. (2000). Model-building strategies and methods for logistic regression. In: W. A. Shewhart, \& S. S. Wilks (Eds.), Applied logistic regression $\left(2^{\text {nd }}\right.$ Ed., pp. 91 142). John Wiley \& Sons Inc.

Instituto de Hidrología, Meteorología y Estudios Ambientales. (2020a). Tiempo y Clima. Seguimiento tiempo. Gráficos de seguimiento diario de precipitación principales ciudades. http://www.ideam.gov.co/web/tiempo-y-clima/graficosseguimiento-diario-precipitacion-principales-ciudades

Instituto de Hidrología, Meteorología y Estudios Ambientales. (2020b). Tiempo y Clima. Seguimiento tiempo. Variabilidad diaria de la temperatura. Instituto de Hidrología, Meteorología y Estudios Ambientales. http://www.ideam.gov.co/ web/tiempo-y-clima/variabilidad-diaria-temperatura

Jayarao, B. M., Pillai, S. R., Sawant, A. A., Wolfganag, D. R., \& Hedge, N. V. (2004). Guidelines for monitoring bulk tank milk somatic cell and bacterial counts. Journal of Dairy Science, 87, 3561-3573. https://doi.org.10.3168/jds.S00220302(04)73493-1

Kelly, P. T., O’Sullivan, K., Berry, D. P., More, S. J., Meaney, W. J., O’Callaghan, E. J., \& O’Brien, B. (2009). Farm management factors associated with bulk tank total bacterial count in Irish dairy herds during 2006/07. Irish Veterinary Journal, 62(1), 36-42.

Mainau, E., Temple, D., \& Manteca, X. (2014). Welfare issues related to mastitis in dairy cows. Farm Animal Welfare Education Centre. https://www.fawec.org/media/com_lazypdf/pdf/fs 10-en.pdf

Medrano-Galarza, C., Zúñiga-López., \& García-Castro, F. E. (2020). Evaluación de bienestar animal en fincas bovinas lecheras basadas en pastoreo en la Sabana de Bogotá, Colombia. Revista MVZ Córdoba, 25(2), Artículo e1708. https://doi. org/10.21897/rmvz.1708

Mekonnen, S. A., Koop, G., Melkie, S. T., Getahun, C. D., Hogeveen, H., \& Lam, T. J. G. M. (2017). Prevalence of subclinical mastitis and associated risk factors at cow and herd level in dairy farms in North-West Ethiopia. Preventive Veterinary Medicine, 145(15), 23-31. https://doi.org/10.1016/j.prevetmed.2017.06.009

Mendoza, J. A., Vera, Y. A., \& L. C. Peña. (2017). Prevalencia de mastitis subclínica, microorganismos asociados y factores de riesgo identificados en hatos de la provincia de pamplona, Norte de Santander. Revista de la Facultad de Medicina Veterinaria y de Zootecnia, 64(2), 11-24. https://doi.org/10.15446/rfmvz.v64n2.67209

Nóbrega, D. B., \& Langoni, H. (2011). Breed and season influence on milk quality parameters and in mastitis occurrence. Pesquisa Veterinária Brasileira, 31(12), 1045-1052. https://doi.org/10.1590/S0100-736X2011001200002

Olde-Riekerink, R. G. M., Barkema, H. W., Veenstra, S., Poole, D. E., Dingwell, R. T., \& Keefe, G. P. (2006). Prevalence of contagious mastitis pathogens in bulk tank milk in Prince Edward Island. Canadian Veterinary Journal, 47(6), 567-572.

Oliver, S. P., Lewis, M. J., Ingle, T. L., Gillespie, E., \& Matthews, K. R. (1993). Prevention of bovine mastitis by a premilking teat disinfectant containing chlorous acid and chlorine dioxide. Journal of Dairy Science, 76, 287-292. https://doi. org/10.3168/jds.S0022-0302(93)77348-8 
Pankey, J. W., Wildman, E. E., Drechsler, P. A., \& Hogan, J. S. (1987). Field trial evaluation of premilking teat disinfection. Journal of Dairy Science, 70(4), 867-872. https://doi.org/10.3168/jds.S0022-0302(87)80085-1

Peters, M. D. P., Silveira, I. D. B., \& Fischer, V. (2015). Impact of subclinical and clinical mastitis on sensitivity to pain of dairy cows. Animal, 9(12), 2024-2028. https://doi.org/10.1017/S1751731115001391

Pinzón-Sánchez, C., \& Ruegg, P. L. (2011). Risk factors associated with short-term post-treatment outcomes of clinical mastitis. Journal of Dairy Science, 94(7), 3397-3410. https://doi.org/10.3168/jds.2010-3925

Ramírez, N. F., Keefe, G., Dohoo, I., Sánchez, J., Arroyave, O., Cerón, J., Jaramillo, M. \& Palacio, L. G. (2014). Herd- and cowlevel risk factors associated with subclinical mastitis in dairy farms from the High Plains of the northern Antioquia, Colombia. Journal of Dairy Science, 97(7), 4141-4150. http://dx.doi.org/10.3168/jds.2013-6815

Ramírez-Vásquez, N., Arroyave-Henao, O., Cerón-Muñoz, M., Jaramillo, M., Cerón, J. \& Palacio, L. G. (2011). Factores asociados a mastitis en vacas de la microcuenca lechera del altiplano norte de Antioquia, Colombia. Revista de Medicina Veterinaria, 22, 31-42. https://doi.org/10.19052/mv.562

Ritter C., Jansen, J., Roche, S., Kelton, D. F., Adams, C. L., Orsel, K., Erskine, R. J., Benedictus, G., Lam, T. J. G. M., \& Barkema, H. W. (2017). Invited review: Determinants of farmers' adoption of management-based strategies for infectious disease prevention and control. Journal of Dairy Science, 100(5), 3329-3347. https://doi.org/10.3168/ jds.2016-11977

Rodrigues, A. C. O., Caraviello, D. Z., \& Ruegg, P. L. (2005). Management of Wisconsin dairy herds enrolled in milk quality teams. Journal of Dairy Science, 88(7), 2660-2671. https://doi.org/10.3168/jds.S0022-0302(05)72943-X

Romero J., Benavides, E., \& Meza, C. (2018). Assessing financial impacts of subclinical mastitis on Colombian dairy farms. Frontiers in Veterinary Science, 5, Article 273. https://doi.org/10.3389/fvets.2018.00273

Romero-Zúñiga J., Rojas-Campos, J., Bolaños-Segura, M., Castillo-Badilla, G., Vargas-Leitón, B., \& Estrada-König, S. (2019). Software Vampp Bovino como instrumento de mediación dialógica entre el sector productivo bovino y la academia. Universidad En Diálogo: Revista De Extensión, 9(2), 99-116. https://doi.org/10.15359/udre.9-2.5

Ruegg, P. L. (2003). Investigation of mastitis problems on farms. Veterinary Clinics of North America: Food Animal Practice, 19(1), 47-73. https://doi.org/10.1016/S0749-0720(02)00078-6

Ruegg, P. L. (2017). A 100-year review: Mastitis detection, management, and prevention. Journal of Dairy Science, 100(12), 10381-10397. https://doi.org/10.3168/jds.2017-13023

Ruegg, P. L, \& Pantoja J. C. F. (2013). Understanding and using somatic cell counts to improve milk quality. Irish Journal of Agricultural and Food Research, 52, 101-117.

Statistical Analysis Sistems Institute. (2016). The SAS system for Windows (Release 9.4.). SAS Institute Inc.

Santivañez-Ballón, C. S., Gómez-Quispe, O. E., Cárdenas-Villanueva, L. A., Escobedo-Enríquez, M. H., Bustinza-Cardenas, R. H., \& Peña-Sánchez, J. (2013). Prevalencia y factores asociados a la mastitis subclínica bovina en los Andes peruanos. Revista Veterinaria y Zootecnia, 7(2), 92-104.

Schabenberger, O. (2005). Introducing the GLIMMIX procedure for Generalized Linear Mixed Models. SAS Users Group International 30 Proceedings, Philadelphia, PA, USA. Paper 196-30. http://www2.sas.com/proceedings/sugi30/19630.pdf 
Schreiner, D. A., \& Ruegg, P. L. (2003). Relationship between udder and leg hygiene scores and subclinical mastitis. Journal of Dairy Science, 86(11), 3460-3465. https://doi.org/10.3168/jds.S0022-0302(03)73950-2

Siivonen, J., Taponen, S., Hovinen, M., Pastell, M., Lensink, B. J., Pyörälä, S., \& Hänninen, L. (2011). Impact of acute clinical mastitis on cow behaviour. Applied Animal Behaviour Science, 132(3-4), 101-106. https://doi.org/10.1016/j. applanim.2011.04.005

Silva-Pulido, R., Alzate-Amelines, J., \& Reyes-Manosalva, C. (2014). Evaluación de las prácticas de ordeño, la calidad higiénica y nutricional de la leche, en el municipio de granada, Antioquia - Colombia. Revista U.D.C.A Actualidad \& Divulgación Científica, 17(2), 467-475.

Stup, R. (2002). Standard operating procedures: managing the human variables. National Mastitis Council Regional Meeting Proceedings, Pennsylvania State University, PA, USA, 2002, 11-18. http://citeseerx.ist.psu.edu/viewdoc/download?d $\mathrm{oi}=10.1 \cdot 1.563 .295 \& \mathrm{rep}=\mathrm{rep} 1 \&$ type $=\mathrm{pdf}$

Suárez, V. H., Martínez, G. M., \& Bertoni, E. A. (2017). Mastitis, a health- related indicator of dairy cow welfare and productivity. Journal of Dairy \& Veterinary Sciences, 4(5), 1-5. https://doi.org/10.19080/JDVS.2017.04.555650

Tolosa, T., Verbeke, J., Piepers, S., Supré, K., \& De Vliegher, S. (2013). Risk factors associated with subclinical mastitis as detected by California Mastitis Test in smallholder dairy farms in Jimma, Ethiopia using multilevel modelling. Preventive Veterinary Medicine, 112, 68-75. http://dx.doi.org/10.1016/j.prevetmed.2013.06.009

Van Straten, M., Friger, M., \& Shpigel, N. Y. (2009). Events of elevated somatic cell counts in high-producing dairy cows are associated with daily body weight loss in early lactation. Journal of Dairy Science, 92(9), 4386-4394. https://doi. org/10.3168/jds.2009-2204

Viguier, C., Arora, S., Gilmartin, N., Welbeck, K., \& O’Kennedy, R. (2009). Mastitis detection: Current trends and future perspectives. Trends in Biotechnology, 27, 486-493. https://doi.org/10.1016/j.tibtech.2009.05.004 